\title{
The Restrictive Measures of Mitigating Covid-19 on People Living with Disabilities and their Families in Zimbabwe
}

\author{
Prince Dzingirayi $^{{ }^{*}}$, Douglas Mambure ${ }^{2}$, Stanley Chiremba $^{3}$, Tracy Chadini ${ }^{4}$ \\ ${ }^{1,3,4}$ Women's University in Africa_Department of Psychology Lecturer \\ ${ }^{2}$ Women's University in Africa__Department of Psychology Coordinator
}

\author{
*Corresponding Author: Prince Dzingirayi, Women's University in Africa _ Department of Psychology \\ Lecturer, Zimbabwe
}

\begin{abstract}
The COVID-19 pandemic has created a profound shock worldwide, with different implications and complications to human life. The pandemic has had and will continue to have unprecedented effects to the health and well-being of many vulnerable groups. People with disabilities are among those at the greatest risk during this crisis because of several factors including: being more likely to have underlying health conditions, being economically disadvantaged, being dependent on others for care, or simply because people with disabilities are disproportionally placed in institutions, incarcerated, or homeless. The conversation research design was used to gather data. Participants were from people living with disabilities or family members who stay with a disabled person. Data was collected through social media platforms of whatsapp and facebook and it was analysed using response scripts. People living with disabilities lack access information on COVID-19. They are vulnerable of the vulnerable population since they are a burden to care during lockdown. Disabled people are susceptible to the transmission of the coronavirus due to their complex conditions. Disabled people were marginalized and their rights were infringed during the restrictive measure of national lockdown. Disabled people were a burdensome during the lockdown since the lockdown was planned without disabled people in mind. Disabled people's voices were often left out of the planning, response, and key decision-making. People with disabilities are the most effective advocates for issues that affect our lives. Qualitative approach was used to understand the impact of Covid-19 on people living with disabilities and their families during the implementation of restrictive measures.
\end{abstract}

Keywords: Disability, COVID-19, Impact, Families.

\section{INTRODUCTION}

Worldwide, the outbreak of COVID-19 had brought shock and unprecedented threats to human survival and development due to its alarming levels of spread and severity. The pandemic is accelerating in an unbelievable speed and it is claiming the life and paralyzing the public health care system across the globe. Fenway Health Institution (2020) explains that the epidemic has been called the "corona virus" in the lay press, since this new virus belongs to that virus family, but the scientific name for the virus is SARS-CoV-2. The disease that the virus causes has been named "coronavirus disease 2019" (abbreviated "COVID-19"). The World Health Organisation (WHO) had raised a red flag and declared the novel corona virus as international disaster. Covid-19 was first discovered in Wuhan, China at the end of 2019 and has now causing critical challenges for public health worldwide. Anjum (2020) describes the (COVID-19) pandemic as a zoonotic coronavirus which crosses species to infect human populations. A new variant of the virus- 501Y.v2 has been emerged again in South Africa and is fast spreading with unnoticeable symptoms which are different from the SARS-CoV-2. The COVID-19 pandemic is creating a profound shock worldwide, with different implications for men and women. The pandemic has had and will continue to have a major impact on the health and well-being of many vulnerable groups (OECD, 2020). People with disabilities are among those at the greatest risk during this crisis because of several factors including: being more likely to have underlying health conditions, being economically disadvantaged, being dependent on others for care, or simply because people with disabilities are disproportionally placed in institutions, incarcerated, or homeless. Choruma (2008) narrates that disabled people's voices are often left out of the planning, response, and key decision-making. People with disabilities are the most effective advocates for issues 
that affect our lives. During pandemics, Carlson (2010) clamors that disability is regarded as objectively bad, as a pitiable condition, 'a personal tragedy' for both the disabled individuals and the community. This entails that during the hard times of covid-19 national lockdown, disabled people are negated, burdensome, exposed without care and lack adequate information of prevention. The disability condition is currently understood from the lens of different models which are the medical, cultural, economic, social, human rights, the limits, the charity and the identity models.

The United Nations Secretary General, António Guterres, called COVID-19 the world's common enemy as it attacks all people regardless of their ethnicity, nationality, faction, or religion (Guterres, 2020). Women and children, the elderly, the homeless, sex workers, people with disabilities, displaced populations, and the marginalised are at the highest risk of bearing the grave consequences of COVID-19 (Brinkerhoff, 2014; Guterres, 2020; Rosoff, 2008; Tsai \& Wilson, 2020; Vearey, 2020).People living with disabilities are the crustal of this study as they viewed as a social welfare in most parts of the world. The socially construction perspective of disability led most developing countries to be lopsided towards the charity model. In this study the term disability and impairment are going to be used interchangeably.

The first confirmed case of COVID-19 infection in African region was reported, in Nigeria, on the 28th February 2020. By 1st April 2020, 43 of 46 sub-Saharan Africa countries had reported confirmed cases of COVID-19 (Prince et al, 2020). COVID-19 is an unprecedented crisis which calls for unprecedented measures. It is affecting the global economy, hitting manufacturing and service sectors, with huge impacts on the labor force. Disabled people constitute the productive labour force. The pandemic has stalwart impact on vulnerable individuals and households who are already bordering poverty may widen inequality gaps and even entrench people in poverty (UN-ESCAP, 2020). The world is facing a grave health and economic crisis and many of us are in lockdown, unable to socialize with friends and family. Kidd \&Sibun (2020) confirm that COVID-19 has caused loss of jobs; salaries are being cut while the self-employed and informal economy workers are experiencing catastrophic losses in income. Those most at risk are older people and people with underlying health conditions, many of whom are disabled. Disabled people are a vulnerable group who are at risk to the outbreak of COVID-19 due to their health and overall social and economic circumstances. Disability enveloped all from children, women, men, and older persons. For disabled persons, the virus poses a greater risk not only because of underlying health conditions that make them more susceptible and vulnerable to the disease, but also because they often find themselves alone, with caregivers and family members unable to support them. This situation is exacerbated by the fact that many disabled persons in Zimbabwe lack social protection. Social distancing will make it more difficult for them to obtain news and information, especially because many are unfamiliar with or have no access to computers and smart phones. For instance the older and disabled persons may also be significantly affected by the economic impacts of COVID-19, with some of them may risk losing their life's savings or overall financial security overnight due to the global financial turmoil (ESCAP, 2020).

According to Coleridge (1993), disability is perceived, by able-bodied people as a tragedy, loss, or a deficiency and these stimulates fear, pity or admiration depending on how the disabled person copes. Malinga (2008) defines disability as the social effects of physical or mental impairments. Which therefore implies disability is something that was created by society. Disability is any restriction or lack of ability to perform an activity in the manner or within the range considered normal for a human being. In reality, disability is defined and perceived differently according to the culture, context, knowledge base, beliefs and values of a society (Choruma, 2008). Disability is socially constructed, that is the way how individuals think about disability and persons with disability and the thinking leads to practices that either exclude or include persons with disabilities.In the African worldview disability is marred with cultural beliefs from its causation to support. In line with the cultural perspective the emerging of COVID-19 has also cultural meanings. Therefore marrying the disability and the novel virus has great traditional beliefs which could have negative impact to disabilities in communities especially during the restrictive measures of lockdown. According to UN Convention on the Rights of Persons with Disabilities, (2009), (Article 25a) state parties should provide persons with disabilities with the same range, quality and standard of free or affordable health care and programs as provided to other persons. The cultural rights in this case are at the apex of being respected since everyone is confused without any solutions to the deadly virus. 
Disability is a very delicate issue in both the north and the south. Trends have indicated that disabled people in the whole universe suffer exploitation, discrimination, segregation and victimization. These anomalies take place in all aspects of life, namely; political, social, economic and even in religion. There are numerous causes of disability including poverty, disease, accidents, violence and war, environmental factors and unhealthy lifestyles, among others. People with disabilities are often labeled as menaces, objects of pity, burdens of charity, and objects of ridicule, holy innocents and sickling. This stereotyping has negative effects and hence the need for change in attitudes by the society. The first step in changing perceptions and attitudes is to understand the experience of disability for those who are disabled (Coleridge, 1993). Therefore the prevalence of the epidemic Covid-19 has shown us that we are all vulnerable.

Containing the pandemic and protecting people is the top priority of all nations.COVID-19 is an ongoing pandemic and currently far from over, strong conclusions could not be drawn with very limited data at present. Nationwide lockdown is being adopted to stop public transport, keep people at their homes and out of their work, and maintain social distancing. Therefore, the world is trying every approach to control the rapid transmission of SAAR-CoV-2 and so the spread of COVID-19 in humans. In an effort to slow the virus' very fast pace spread, a large number of countries is adopting the strategy of practicing social distancing and telling people to stay in their homes through implementing the strict lockdown.(Anjum,2020). Through ramification of international measures to curb the spread of the novel corona virus, the measures had caused vulnerable disabled population more vulnerable. Therefore this motivated this tractate to focus on the psychological impact of restrictive measures of mitigating COVID-19 on disabled people in Zimbabwe.

\section{LITERATURE REVIEW}

\subsection{The Global Overview of Covid-19}

Global health experts and African governments have expressed concern about the spread of COVID19 and potential for more than 2 million deaths in sub-Saharan Africa if no action is taken (Walker et al, 2020). Human beings as innovative creatures have sought new ways in which to curb the devastating effects of COVID-19. Since the COVID-19 outbreak was first diagnosed, it has spread over the globe. The pandemic is having a noticeable impact on global economic growth. Estimates so far indicate the virus could trim global economic growth by as much as $2.0 \%$ per month if current conditions persist. Global trade could also fall by $13 \%$ to $32 \%$, depending on the depth and extent of the global economic downturn (Gript, 2020). The full impact will not be known until the effects of the pandemic peak. Tsai \& Wilson (2020) highlight that the infection has infected more than 3.2 million people, United States of America has the highest fatalities. More than 80 countries have closed their borders to arrivals from countries with infections, ordered businesses to close, instructed their populations to self-quarantine, and closed schools to an estimated 1.5 billion children.

The world is rightly focused on measures to suppress COVID-19 transmission and protect the most vulnerable population. Rosenthal et al. (2020) assert that it is not possible for them to observe social distancing, let alone self-isolate due to overcrowding and abysmal living conditions which provide a breeding ground for exposure and transmission. In addition, with over a billion people living with disabilities (PLWD) globally, it is believed that COVID-19 will likely have ruinous consequences on this group of people, thus making them susceptible to 'increased morbidity and mortality' (Armitage \& Nellums, 2020).

COVID-19 is spread mainly through discharge from the nose or droplets of saliva when an infected person sneezes or coughs. It is associated with fever, tiredness, dry cough, sore threat, aches and pains, and shortness of breath and has no specific vaccine or treatment although clinical trials examining possible treatments are underway (WHO, 2020a, 2020b). To curtail its spread, sanitising hands or washing them regularly using soap and water, social distancing, staying home when unwell, and covering one's mouth and nose when coughing and sneezing are some of the recommended remedies (Prem et al., 2020; Rosenthal, Ucci, Heys, Hayward, and Lakhanpaul, 2020; WHO, 2020c).

\subsection{Effects of COVID-19}

The COVID-19 has caused alarm, despondency, fear and desperation among the world's population (Hargreaves, Kumar, McKee, Jones, \& Veizis, 2020). It affects the experiences of individuals, 
families, groups, and communities on a diurnal basis in their local environments and points to the intricate and 'intimate connections, the global and the local' (Murenje \& Kimone, 2020). Social isolation measures and quarantines have proved to have a negative effect on human being's physical integrity, leading to a sharp rise in social problem such as domestic violence worldwide (Armocida,2020)

Research in Singapore and Australia has proved that the impact of COVID-19 is so tremendous due to the concentration of economic activities, demographics, urbanization, and difficult progress. Therefore this current pandemic has caused interconnected crises ranging from physical, political, social, economic and psychologically. In Singapore current trends of research shows that economic crises hit women harder than men because they are often underrepresented in the informal sector and they suffer simultaneously as public-sector workers. The lockdown has significant effects to disabled women who are already vulnerable. No one is safe from the novel coronavirus, young people are infected and likely to survive as carriers but to the older people the virus causes instant death.

\subsection{Disability in Zimbabwe}

The Zimbabwe Ministry of Health and Child Care (MOHCC)'s (2013) survey results revealed that, $7 \%$ of the Zimbabwe's population have disabilities, entailing that over 900000 of the 13 million Zimbabweans are disabled. Further, $25 \%$ of disabled people acquire disability at birth or before the age of five years. The physical and visual impairments are the most common forms of disability respectively. Natural environment is perceived as the most common cause of disability (Malinga, 2013). IRIN Africa (2015) swifts that around one in four acquire disability at childhood age while $45 \%$ of individuals with disability have acquired their disability before the age of 20 years. The survey results further informed us that fewer individuals who are disabled access formal education. It was also discovered that fewer disabled people had higher rates of formal employment. In the same vein, it was also noted that a substantive aggregate of disabilities that are occurring early in the life are preventable. Therefore during the pick of COVID-19 the disabled people experienced some inhumane treatments which included segregation, insults, stigmatization and social seclusion in accessing information and services of the novel virus. For instance social distance was a barrier to a wheelchair bound. Zimbabwe is a collective society which views disability from a cultural lens linked to equalization of opportunities. It is the society that determines what is normal or abnormal. There is a strong relationship between disability and culture. Cultural factors and practices contribute significantly towards the way in which disabled people are being regarded and treated in many societies.

\subsection{Types of Disabilities}

There are six major disabilities which can affect anyone at any point in life. These are:

1. Fits

2. Visual/seeing disabilities

3. Physical/ moving disabilities

4. Hearing/speech(communications) disabilities

5. Learning (intellectual cognitive) disabilities

6. Strange behaviour (resulting from psychotic mental illness for example manic depressive psychosis, schizophrenia or post-traumatic stress disorder).

The main issues that people with disabilities are concerned about are; prevention of disability, health care, rehabilitation, public education awareness, barrier free access, transport, communication, education, employment, human resource development, social welfare, social security, housing and sport and recreation (Cockburn, 2002). In support, WHO (2011) in Bae, Dube, Khumalo, and Onyewandume (2013)persons with disability are often marginalised and belong to the poorest segments of the society. Most of these persons live in developing countries and very often without the optimal technical, medical or social support that could improve their quality of life. Stack, (2013) posits that empowerment means that people with disability have access to the fundamental rights and freedom that other people are granted. 
Choruma (2006) propounds that a number of negative beliefs on the causes of disabilities persist in Zimbabwe, such as associating disability with witchcraft or maternal promiscuity. The culture in Zimbabwe is still to look at disability as a curse. Generally there is limited social acceptance of people with disabilities by their family (particularly their fathers and paternal relatives) and the communities they live in. Birth of a disabled child usually results in the marriage breaking as the father in most cases will blame the mother for giving birth to a disable child.

\subsection{Models of Disability}

The importance of shaping disability-friendly is a practical testament of fact during pandemic such as COVID-19. Models of disability offer a theoretical framework to understand different ways people view beliefs about disability and help to explain their perspectives. There are various models of disability that shape people's perceptions and ideas about people with disabilities. Understanding models is the spinal cord of development and disability worldwide. The principle of interpreting the importance of models of disability in shaping perceptions of protecting humanity to people with disabilities is so noble in this article. The answers of planning with disability in mind is in the utilization of the model which are the charity, social, medical, identity, economic, human right, limits and cultural model. This research is going to dwell on medical, charity, social, human and identity models

\subsubsection{Disability Medical Model}

Disability is seen as a medical problem that resides in the individual. According to Retief \&Letšosa (2017) persons with disabilities are expected to avail themselves of the variety of services offered to them and to spend most of their time in the role of patient. According to the medical model abnormal or disorder are preferred terms which automatically deviate from what is normal for people living with disabilities (PWD). Creamer (2009) reinforces that labels such as 'invalid', 'cripple', 'spastic', 'handicapped' and 'retarded' are all derived from the medical model. This approach reflects that PWD are not comparable with their able-bodied counterparts. In this regards medical professional who subscribe to the medical model tend to treat people as problems to be solved, without considering various aspects related to the person's life as a whole (Thomas \& Woods 2003). The work of Pfeiffer (2003) avers that people living with disabilities are an embarrassment to the community and are viewed as failures since there is no current cure which had been discovered to eliminate disability. The medical model confines people living with disabilities to characteristics of a sick person which are: exempted from performing normal social roles and responsibilities of his or her own state. The other characteristic is of being deprived to claim full legitimacy and viewed as in needy. This creates some short comings the medical model ascertain that disabled people are a challenge during the restrictive measures of curbing corona virus. Therefore the embarrassment lenses tend to discard the rights of disabled people living them in mucky waters and subject them to infectious environment of the pandemic.

\subsubsection{The Social Model: Disability as a Socially Constructed Phenomenon}

Disability is socially constructed. This means that physical and social environment impose limitations upon certain categories of people Barnes, Mercer \& Shakespeare (2010) argues that it is society which disables people with impairments and therefore any meaningful solution must be directed at societal change rather than individual adjustment and rehabilitation. UPIAS (1976) emphasizes that disability is a situation, caused by social conditions, which requires for its elimination, (a) that no one aspect such as incomes, mobility or institutions is treated in isolation, (b) that disabled people should, with the advice and help of others, assume control over their own lives, and (c) that professionals, experts and others who seek to help must be committed to promoting such control by disabled people. This notion goes in support of the saying "nothing for us without us". This means we need to involve disabled people in all decision making roles so that they can contribute for themselves. During decision of implementing the restrictive roles of lockdown disabled people needs to participate significantly. Disability is a socially constructed disadvantage or restrictions which constitutes a particular form of social oppression to impaired people. Purtell (2013) observes that disabled people are people who are "disabled" by the society they live in and by the impact of society's structures and attitudes. The social model helps people to understand the underlying social factors that shape peoples' understanding of disability. It is the role of the social model to explain why so many PWDs are living in poverty. 


\subsubsection{The Identity Model}

This model shares the social model's understanding that the experience of disability is socially constructed, but differs to the extent that it 'claims disability as a positive identity' (Brewer et al. 2012:5). Disability is primarily defined by a certain type of experience in the world such as social and political experience of the effects of a social system designed without disabled people in mind. The identity model aligns much more to the social model, it is less interested in the ways environments, policies, and institutions disable people. Therefore during pandemics the identity of an individual can expose him/her since everyone will be after his own safety. In terms of disabled individuals who will identify the risks they face and what kind of interventions would be appropriate. Covid-19 is simply equated to the war situation in which everyone is running away with his/her life.

\subsubsection{The Human Rights Model}

Some researchers treat the social model and the human rights model as virtually synonymous. The human rights model moves beyond explanation, offering a theoretical framework for disability policy that emphasises the human dignity of PWDs (Degener, 2017). The human rights model respects the fact that some PWDs are indeed confronted by challenging life situations and such factors should be taken into account in the development of relevant social justice theories (Degener 2017). The human rights model offers constructive proposals for improving the life situation of PWDs.

\subsection{Aim of the Study}

To understand the impact of COVID-19 on people living with disabilities and their families during the implementation of restrictive measures

\section{MeTHOdOLOGY}

The methodology section includes research design, participants and setting, instruments, data collection and analysis procedures. The research shall employ qualitative methods to understand the impact of COVID-19 on people living with disabilities and their families during the national lockdown in Harare.

\subsection{Research Design}

This research employed the conversation research design which qualitative in nature. According to Kovach (2019) the conversational method is significance in this study because it is a method of gathering knowledge based on oral storytelling. Conversation method involves dialogic participation that holds a deep purpose of sharing story as a means to assist others. Thomas (2005) goes on to state that storytelling has a holistic nature that provides a means for sharing remembrances that evoke the spiritual, emotional, physical, and mental. Therefore this study focuses on the impact of COVID-19 on people living with disabilities and their families during the national restrictive measures.

\subsection{Participants and Setting}

This study involves disabled people and families members who stay with someone with disability condition in Harare. An equal representation of gender and varying disability conditions was employed. Snow ball and purposive sampling was used in the study to select disabled people and family members. A family member of a minor with disability was used.

\subsection{Data Collection}

The researchers gathered data through interviews with open ended questions in which participant answered social media platforms of WhatsApp and Facebook. The research also employed the use of interactions with participants via text and audios. Responses were recorded in a document form.

\subsection{Data Analysis}

Thematic content analysis was used to analyse data. The researcher grouped all the response transcripts into interesting phrases and themes. Data familiarization is a key to thematic analysis as it is used for qualitative methods. Howitt and Cramer (2010) describe that the process vary according to circumstances including the researcher's expectations about the direction in which the analysis proceed. 


\subsubsection{Ethical Guidance}

Social science research is guided by honouring the research ethics. In carrying out this research the principle of protecting the participants was honoured. Stopher (2012) indicates that ethics create a morally justification of displaying research behaviour which is human abuse free. This research takes into considerations of informed consent, autonomy, competence, confidentiality and anonymity. Since the study was carried during the COVID-19 lockdown anonymous interview questions was delivered to participants.

\section{RESULTS AND DISCUSSION}

\subsection{Covid-19 National Lockdown and Disabled People's Way of Life}

The study revealed the impact of national lockdown during covid-19 restrictive measure to people living with disabilities. The restriction measures and closing of social amenities has significantly affected the life of people living with disabilities. Prior the national lockdown the disabled people were able to fend for themselves through informal activities of vending. One participate indicated that "I used to survive and feed my family by selling fruits, music disc, vegetables, airtime and small items such as cigarettes". Participant 2 said "I used to survive from begging in buses and in streets". Participant 3 insists that "I used to get help from well-wishers in social gatherings such as churches and individuals". Participant 4 fumes that "my skill is now in trouble I can't go to town to get my skin lotion because I don't have a letter and security officers were only tolerating with someone with a letter" The national lockdown and restrictive measures had paralyzed the sources of income since most of them were informally employed. The vending activities were halted during the lockdown. The pandemic has had and will continue to have a major impact on the health and well-being of many vulnerable groups (OECD, 2020). People living with disabilities, who are dependent on support for their daily living find themselves in isolation and unable to survive during lockdown days. The current restrictive measures which go with COVID-19 adversely affect persons living with disabilities by preventing families and bread winners from working thereby imparting negatively on income of their household. The research also noted elements of overprotection of disabled people from their family members. The protection end up as discriminatory and abuse to individual family members in the community. The mentality of the charity approach from the law enforcement agents who were roaming around the streets was noticed. The disabled people who operate as vendors of airtime were left out to carry their daily activities hence exposing themselves to the novel coronavirus. People with disabilities face stigmatisation, social isolation and are not considered as part of a general society.

\subsection{Access of Information on COVID-19 and National Lockdown}

Most people living with disabilities did not get the information of the epidemic in time. They lack full information on health issues related to wearing of masks, hand washing with sanitizers, sneezing in elbow and there are poor communication modes such as Braille, sign language, whatsapp, face book, audio radio, television, twitter and talking boards. Due to deficiency of information some of them indicated that they were surprised by the presents of security personnel in the streets. Mental retarded were still confused of what was going on. One family member echoed that, my daughter is being surprised of putting on masks and refused on putting on a mask. Participant 5 supports that, there is no materials about covid-19 on Braille. This indicates that people living with disabilities are a vulnerable of the vulnerable, since the system had shunned them with information of the epidemic. In support, WHO (2011) in Bae, Dube, Khumalo, and Onyewandume (2013) persons with disability are often marginalised and belong to the poorest segments of the society. Those with hearing impairment complained that there is no information in sign language. The family member said, "police officer are unable to communicate with sign language, my son was beaten by the police cause of loitering, yet he was unaware of what was happening, my son used to know what was happening through watching the television but could not do it because there is no electricity". This means that most disabled people were left out and they had patch information of the transmission and prevention of the novel corona virus. Choruwa (2007) postulates that a disability is a socially constructed phenomenon and challenges that there is need to plan with disability in mind. Therefore there is no in-depth information from the media such as radios about covid-19. Many persons living with disabilities have preexisting health conditions that make them more susceptible to contracting the virus. From the response disabled people's voices are left out of the planning and key decision making. People with mental 
retardation are at high risk this lockdown period because of their uncontrolled public presents that may impede efforts to break transmission chain. Disability is a complex condition hence some people living with psycho-social disabilities and autistic are not able to cope with strict confinements at home. This means that the lockdown had a negative impact to people living with disabilities. Barriers for persons living with disabilities in accessing health services and information are intensified.

\subsection{Social Assistance}

Covid-19 lockdown had negatively affected the social live of vulnerable people. People living with disabilities were a burden to the family members and were ill-treated due to poverty. Assistance is a subset of the charity model. The wheelchair bound was susceptible to the transmission of the deadly coronavirus since there is no way they could survive without holding the wheels for their mobility. Participant 3 complaints that, I hate being assisted because assistance thwarts my rights leading to an abuse. I need to work for myself. Participant 5 posit that although the government has availed funding 180 rtgs for the under-privileged, however not all who are supposed to access it are getting it. Those who are failing to access are relying on handouts from neighbours and poor parents. Only 180rtgs is being accessed by those in need in towns but those in rural areas are not aware. There is no money, no sanitizers, and masks. The monetary assistance were not enough due to the skyrocketing of the basic goods and services. Participant 2 indicates that, "people living with disabilities does not need monetary assistance by there is need to assess their needs and wants. People who live with them need to be assisted also". According to the findings, one of the major risks of the virus transmission is believed to be via contacts with infected persons or breathing in contaminated droplets therefore this group is at higher risk of contracting COVID-19. People who assist them might transmit the virus to them through coughing and touching. Due to their conditions some of the disabled people with multiple disabilities could not put on masks. During this lockdown period, there is danger that people living with disabilities may be left unassisted by their helpers for fear of contracting the virus.

\subsection{Getting Back to Normal Life}

All people living with disabilities and their families call for the end of the national lockdown so that they go back to their usual surviving modes. Participant 2 narrates that, "we wish lockdown can end so that we can go back to our normal activities of vending, begging in streets and buses". Another participant concur that, "it's better to die with COVID-19 than to die of hunger. We are getting poorer every hour due to national lockdown".

\section{CONCLUSION AND RECOMMENDATION}

Conclusively, this study found that COVID-19 national restrictive measures brought more harm than good to disabled people. Panic response of coronavirus has led to communities to view disability as an object of burden. The issues of disability had gained recognition yesteryear but the sudden emerging of the pandemic had mishap conception in the communities. The pandemic lockdown had caused grip and created numerous disruptions to the livelihoods coiled with geo-socioeconomic effects. It is crucial to note that a good understanding of a person with a disability goes far beyond the individual characteristics of the person and places him or her in the framework of a wider social-cultural system even during time of pandemics such as coronvirus. The study had the following recommendations:

- The authorities should mobilize for the availability of valid informative material which does not make an individual disabled such as the Braille, sign language interpreters, website audios, radio stations and more.

- There is need to have a well-functioning social protection and universal healthcare systems which should cater for equity and equality in getting essential health-care services and access to safe, effective, quality and affordable essential treatments for all

- The authorities need to plan with vulnerable population in mind.

- The central government should ensure that food provision schemes include persons with disabilities.

- To ensure that people living with disabilities get protective equipment for COVID-19. 
- Government need to provide financial compensation for self-employed persons with disabilities who would have find their income reduced.

- The central government needs to establish tax relief incentives that may help to alleviate the financial situations of persons living with disabilities in COVID-19 pandemic.

\section{CONCLUSIONS}

It emerged from the present study that the majority of disabled people were left out in decision making during the COVID-19 lockdown and they did not get information on the spread and control of the coronavirus. The study reveals that disabled people were susceptible to the novel virus and their living standards were reduced to abrupt poverty hence became a burden in the family. People living with disabilities wished the lockdown could end so that they can get back to their normal way of living since most of them were surviving on informal trading. Therefore the national lockdown brought more harm than good to the disabled population.

\section{REFERENCES}

[1] Anjum, N., A. (2020). Good in The Worst: COVID-19 Restrictions and Ease in Global Air Pollution, https://www.scopus.com/authid/detail.uri?authorId=23097123400

[2] Armitage, R. \& Nellums, L. B. (2020). The COVID-19 response must be disability inclusive. Lancet Public Health, 1. https://doi.org/10.1016/S2468-2667(20)30076-1

[3] Armocida, B., Formenti, B., Ussai, S., Palestra, F., \& Missoni, E. (2020). The Italian health system and the COVID-19 challenge. Lancet Public Health, 1. https://doi.org/10.1016/S2468-2667(20)30074-8

[4] Brinkerhoff, S. (2014). Social worker (careers with character). Broomall, PA19008: Mason Crest.

[5] Briskman, L. (2019). The people's inquiry into detention: Social work activism for asylum-seeker rights. Journal of Sociology 56(1), 100-114. https://doi.org/10.1177/1440783319882540

[6] Choruma, T. (2007). The forgotten tribe. People with disabilities in Zimbabwe. London: Progressio.

[7] Disabled Persons Act (1992). Disability rights education and defend fund.

[8] IRIN Africa (2015). Zimbabwe: Disabled children embattled by education policy.

[9] Gript (2020, March 31). 60 minutes: Wuhan whistle-blower Dr Ai Fen "has disappeared". Gript. Retrieved from gript.ie/60-minutes-wuhan-whistle-blower-dr-ai-fen-has-disappeared/

[10] Guterres, A. (2020). Coronavirus disease (COVID-19). Retrieved https://www.un.org/en/un-coronaviruscommunications-team/fury-virus-illustrates-folly-war

[11] Hargreaves, S., Kumar, B. N., McKee, M., Jones, L. \& Veizis (2020). Europe's migrant containment policies threaten the response to covid-19. BMJ 368, 1-2. doi: 10.1136/bmj.m1213

[12] Hokenstad, M. C. T. (2007). Social work education for disaster recovery and community building. Paper presented at the International Seminar on Disaster Planning, Management and Relief, Barbados, West Indies, January 10-12, 2007.

[13] Human Rights Watch (2020). Human rights dimensions of COVID-19 response. Retrieved from https:// www.hrw.org/news/2020/03/19

[14] Keller, A. S. \& Wagner, B. D. (2020). COVID-19 and immigration detention in the USA: Time to act. Lancet Public Health, 1-2. https://doi.org/10.1016/S2468-2667(20)30081-5

[15] Kidd, S. and Sibun, M. (2020). What has the COVID-19 taught us about social protection, the Pathways' Perspectives on social policy in international development.

[16] Kinner, S.A., Young, J. T., Snow, K., Southalan, L., Lopez-Acuña., O’Moore, Ė. (2020). Prisons and custodial settings are part of a comprehensive response to COVID-19. Lancet Public Health 5, e188-e189. https:// doi.org/10.1016/S2468-2667(20)30058-X

[17] Liasidou, A. (2014). Disability discourses and human rights law: A case study based on the implementation of the UN convention on the rights of people with disabilities, discourse: Studies in the cultural policies of education. Retrieved from http//:dx.doi.org/10 on 30 June 2014

[18] Malinga, J., T. (2008). Levels of awareness on the African decade of disabled persons (ADDP) by people with disabilities in Zimbabwe. Berlin: Lambert Academic Publishing.

[19] Marlowe, J. (2019). Refugee resettlement, social media and the social organization of difference. Global Networks, 1-18. 
[20] Prem, K., Liu, Y., Russell, T. W., Kucharski, A. J., Eggo, R. M., \& Davies, N. (2020). The effect of control strategies to reduce social mixing on outcomes of the COVID-19 epidemic in Wuhan, China: A modelling study. Lancet Public Health, 1-10. https://doi.org/10.1016/S2468-2667(20)30073-6

[21]Retief, M. \& Letšosa, R .(2017). Models of disability: A brief overview. HTS Teologiese Studies/ Theological Studies 74(1), a4738. https://doi.org/ 10.4102/hts.v74i1.4738

[22] Rosenthal, D. M., Ucci, M., Heys, M., Hayward, A., \& Lakhanpaul, M. (2020). Impacts of COVID-19 on vulnerable children in temporary accommodation in the UK. Lancet Public Health, 1-2. https:// doi.org/10.1016/S2468-2667(20)30080-3

[23] Rosoff, P. M. (2008). The ethics of care: Social workers in an influenza pandemic. Social Work in Health Care 47(1), 49-59. doi: 10.10180/009813801970814

[24] Schrooten, M., Geldof, D., \& Withaeckx, S. (2016). Transmigration and urban social work: Towards a research agenda. European Journal of Social Work, 19(1), 18-30. http://dx.doi.org/10.1080/13691457. 2014.1001725

[25] Tsai, J. \& Wilson, M. (2020). COVID-19: A potential public health problem for homeless populations. Lancet Public Health 5, e186-e187. https://doi.org/10.1016/S2468-2667(20)30053-0

[26] UNITED NATIONS-ESCAP (2020).The Impact and Policy Responses of Covid-19 In Asia and the Pacific,

[27] Walker, P., Whittaker C., Watser, O., et al (2020). The Global Impact of COVID-19 and Strategies for Mitigation and Suppression. WHO Collaborating Centre for Infectious Disease Modelling, MRC Centre for Global Infectious Disease Analysis, Abdul Latif Jameel Institute for Disease and Emergency Analytics, Imperial College London. https://www.imperial.ac.uk/media/imperialcollege/medicine/sph/ide/gida fellowships/Imperial-College-COVID19-Global-Impact-26-03-2020.pdf

[28] Weir, K. (2020). Seven crucial research findings that can help people deal with COVID-19. Retrieved from apa.org/news/apa/2020/03/covid-19-research-findings

[29] Williams, C. \& Graham, M. (2014). 'A world on the move': Migration, mobilities and social work.British Journal of Social Work 44(Supplement 1), i1-i17. doi: 10.1093/bjsw/bcu058

[30] World Health Organization (WHO) (2020a). Coronavirus. Retrieved from https://www.who.int/healthtopics/coronavirus\#tab=tab_1

[31] World Health Organization (WHO) (2020b). Coronavirus. Retrieved from https:// www.who.int/healthtopics/coronavirus\#tab=tab_3

[32] World Health Organization (WHO) (2020c). Coronavirus. Retrieved from https:// www.who.int/healthtopics/coronavirus\#tab=tab_2

\section{AUTHORS' BIOGRAPHY}

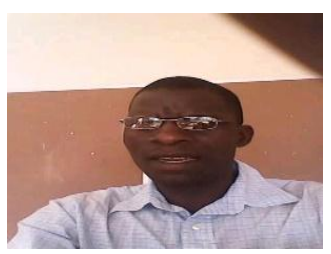

Prince Dzingirayi, is a $\mathrm{PhD}$ student at the University of KwaZulu-Natal and he is a Psychology lecturer at Women's University in Africa. He is a registered Psychologist in Zimbabwe. He holds several qualifications which include a Master in Community Psychology, Bachelor of Social Sciences Honours in Psychology and a Diploma in Education. He published more than a dozen of research papers with different journals. His research interests are centred on indigenous knowledge system (IKS), Community development, mental health issues, disability studies, Psychological interventions and assessment, and behavioural challenges.

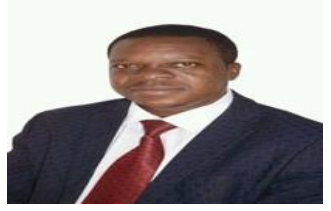

Douglas Mambure, is a senior psychology lecturer at Women's University in Africa. He is a community psychologist, an ordained clergy with an international exposure and is a motivational speaker. $\mathrm{Mr}$ Mambure is a strategist leader gifted in empowering, building and transform lives. He is a philanthropist who pioneered charitable organisations and a former head of humanitarian sector for non-governmental organisation in Zimbabwe. His research interest is on psychotherapy, counselling and psychology of religion.

Stanley Chiremba, is a lecturer at Women's University in Africa. He is a holder of Master in clinical psychology from Muhammadiyah University in Surakarta, Indonesia. He is passionate in generating new knowledge.

Dr Tracey Chadini, is a lecturer at Women's University in Africa. She holds a Doctor of Philosophy in Special Needs Education (Atlantic International University), Master of Science in Special Needs Education (Zimbabwe Open University), Bachelor of Science (Hons) Psychology (Zimbabwe Open 
The Restrictive Measures of Mitigating Covid-19 on People Living with Disabilities and their Families in Zimbabwe

University) and a Diploma in Education. Her research interest is on psychological wellness and safety, epidemic diseases and psychological interventions.

Citation: Prince Dzingirayi, et.al. "The Restrictive Measures of Mitigating Covid-19 on People Living with Disabilities and their Families in Zimbabwe" International Journal of Humanities Social Sciences and Education (IJHSSE), vol 8, no. 2, 2021, pp. 225-235. doi: https://doi.org/10.20431/2349-0381.0802023.

Copyright: (C) 2021 Authors. This is an open-access article distributed under the terms of the Creative Commons Attribution License, which permits unrestricted use, distribution, and reproduction in any medium, provided the original author and source are credited. 